\title{
Incidence of Fruit Borer Helicoverpa armigera (Hubner) on Ashwagandha in Shivamogga
}

\author{
Syed Khadeeru Rehaman ${ }^{1 *}$, S. Pradeep ${ }^{2}$ and R. Dhanapal ${ }^{3}$ \\ ${ }^{1}$ School of Agriculture Sciences and Forestry, Rai Technology University, \\ Bangalore 561204, Karnataka, India \\ ${ }^{2}$ Department of Agricultural Entomology, University of Agricultural and Horticultural \\ Sciences, Shivammogga -577225 (Karnataka), India \\ ${ }^{3}$ Institute of Agricultural Sciences, Banaras Hindu University, Varanasi- 221005 \\ (Uttar Pradesh), India \\ *Corresponding author
}

\section{A B S T R A C T}

Keywords

H. armigera,

Weather parameters,

Correlation,

Significant

Article Info

Accepted:

10 February 2018

Available Online:

10 March 2018

\begin{abstract}
Shivamogga region is one of the richest sources of biodiversity in the world, having a wide range of medicinal and aromatic plants. The present studies were undertaken to record the incidence of fruit borer Helicoverpa armigera on Ashwagandha. Fruit borer, Helicoverpa armigera (H.) (Noctuidae: Lepidoptera) is one of the pest of ashwagandha in Shivamogga. Its incidence in cultivated ashwagandha during 2014-2015 was studied at Organic Farming Research Center (OFRC) Shivamogga. The larval incidence and per cent fruit borer damage on ashwagandha at OFRC, Shivamogga was recorded during September 2014 to February 2015 and its occurrence was peak during third week of December i.e., 1.3 larvae per plant and 41.40 per cent respectively. A non-significant correlation was observed between the larval population of $H$. armigera and weather factors. The correlation between fruit damage and weather factor was found negatively significant to rainfall and nonsignificant to temperature and relative humidity.
\end{abstract}

\section{Introduction}

Ashwagandha [Withania somnifera (L.) Dunal], also known as Indian ginseng is an important medicinal plant used in Ayurvedic formulations to treat various aliments of mankind (Sangwan et al., 2004).

The plant is very hardy and drought resistant and now cultivated as rainfed crop in almost all the parts of country due to its high value and export potential (Chandranath and Katti,
2010). The crop is reported to attack by many insect pests (Ramanna et al., 2010). $H$. armigera is one of the major pests of ashwagandha causing severe damage to crop.

The incidence of fruit borer varies from place to place and year to year due to prevailing environment. Information on the incidence of $H$. armigera in the region is very meager. Thus to understand the pest status, incidence of the pest on ashwagandha in the region present investigation is attempted. 


\section{Materials and Methods}

Studies were conducted during 2014-2015 in organic framing research center, College of Agriculture, Shivamogga.

\section{Incidence of $\boldsymbol{H}$. armigera}

A study was conducted at OFRC, College of Agriculture, Navile, Shivamogga in an area of 100 sq.mt to determine the incidence of fruit borer Helicoverpa armigera on Ashwagandha during cropping period from September 2014 to March 2015. The population fluctuation of fruit borer was recorded at weekly interval during cropping seasons. The crop was monitored weekly interval for the incidence of fruit borer damage in Ashwagandha. The data on incidence of the fruit borer on ashwagandha for durations were presented graphically with important weather parameters namely temperature and relative humidity of same period. Correlation of co-efficient (r) was worked out between incidence of fruit borer and important weather parameters during the period to find out the influence of weather on population fluctuation.

For the sampling, ten plants were randomly selected and number of insects was recorded per plant. The fruit borer damage was assessed by counting number of infested and healthy pod. Total number of fruits and fruits damaged by fruit borer in each plant was recorded and per cent infestation was worked out by using formula.

Total no. of infested fruits

Percent infestation = --------------- X 100

Total no. of fruits in plant

After compiling the data on the incidence of fruit borer, weather parameters viz., maximum and minimum temperature, relative humidity and rainfall factors were subjected to simple correlation and multiple regression analysis.

\section{Results and Discussion}

The incidence was monitored from September 2014 to February 2015 at weekly interval. The incidence of $\mathrm{H}$. armigera commenced from second week of October 2014 and continued till fourth week of February 2015. During second week of October 2014, the incidence of $H$. armigera was less (0.3 larvae per plant). The more number of larvae was observed during different weeks of December 2014 and reached the maximum of 1 to 1.3 larvae per plant during third week of December 2014 and then declined during last week of January 2015 (Plate 1).

The Correlation between larval population of $H$. armigera and weather factors exhibited non-significant correlation with all the weather parameters (Table 1).

The incidence of per cent fruit borer damage was commenced from second week of October 2014 and continued till fourth week of February 2015. During second week of October 2014, the initial damage of fruit borer was at a lower level $(2.80 \%)$. The percentage of damage increased to 4.6 per cent in the next third week of October.

The heavy percentage of damage was observed during different weeks of December 2014 and reached the maximum of 41.40 per cent during third week of December 2014 and then declined during last week of January 2015 (14.20 \%) (Table 3). The results obtained are closely related with the Rammana (2009) who reported that the percent fruit borer damage was gradually increased in August $(20.5 \%)$ and reached to peak during the fourth night of November (43\%) on ashwagandha (Figure 1 and 2).

The data pertaining to relationship between fruit borer damage and weather parameters is presented in the Table 2 . 
Table.1 Correlation co-efficient values between larval incidence of $H$. armigera and weather parameters during 2014-2015

\begin{tabular}{|c|c|c|c|c|c|}
\hline \multirow[t]{2}{*}{ Insect pest } & \multirow{2}{*}{$\begin{array}{l}\text { Rain fall } \\
\text { (mm) }\end{array}$} & \multicolumn{2}{|c|}{ Temperature $\left({ }^{0} \mathrm{C}\right)$} & \multicolumn{2}{|c|}{ Relative humidity (\%) } \\
\hline & & Maximum & Minimum & Morning & Evening \\
\hline H. armigera & -0.359 & 0.324 & -0.104 & -0.276 & -0.159 \\
\hline
\end{tabular}

Table.2 Correlation co-efficient values between per cent fruit borer damage of Ashwagandha and weather parameters during 2014-2015

\begin{tabular}{|l|c|c|c|c|c|}
\hline \multirow{2}{*}{ Factor } & $\begin{array}{c}\text { Rain fall } \\
(\mathrm{mm})\end{array}$ & \multicolumn{2}{|c|}{ Temperature $\left({ }^{0} \mathrm{C}\right)$} & \multicolumn{2}{c|}{ Relative humidity (\%) } \\
\cline { 2 - 6 } & Maximum & Minimum & Morning & Evening \\
\hline $\begin{array}{l}\text { Per cent fruit } \\
\text { borer damage }\end{array}$ & $-0.456^{*}$ & 0.168 & -0.242 & -0.114 & -0.004 \\
\hline \begin{tabular}{l}
$\mathrm{n}=23$ \\
\hline
\end{tabular} & & & & & \\
\hline
\end{tabular}

* Significant at $5 \% \mathrm{r}=0.413$

Table.3 Multiple linear regression of per cent fruit borer damage of Ashwagandha with weather parameters during 2014-2015

\begin{tabular}{|c|c|c|c|c|c|c|c|}
\hline Factor & Constant A & $\mathbf{X 1}$ & $\mathbf{X 2}$ & $\mathbf{X 3}$ & $\mathbf{X} 4$ & $\mathbf{X 5}$ & $\mathbf{R}^{2}$ \\
\hline Per cent fruit borer damage & -146.36 & -0.371 & 0.456 & -0.32 & -0.09 & 0.579 & 0.331 \\
\hline
\end{tabular}

Where,

$\mathrm{X}_{1}$ : Rain fall

$\mathrm{X}_{2}$ : Maximum temperature

$\mathrm{X}_{3}$ : Minimum temperature

$\mathrm{X}_{4}$ : Morning humidity

$\mathrm{X}_{5}$ : Evening humidity

$\mathrm{R}^{2}$ : Coefficient of determination

Fig.1 Average weekly incidence of H. armigera on ashwagandha during 2014-2015

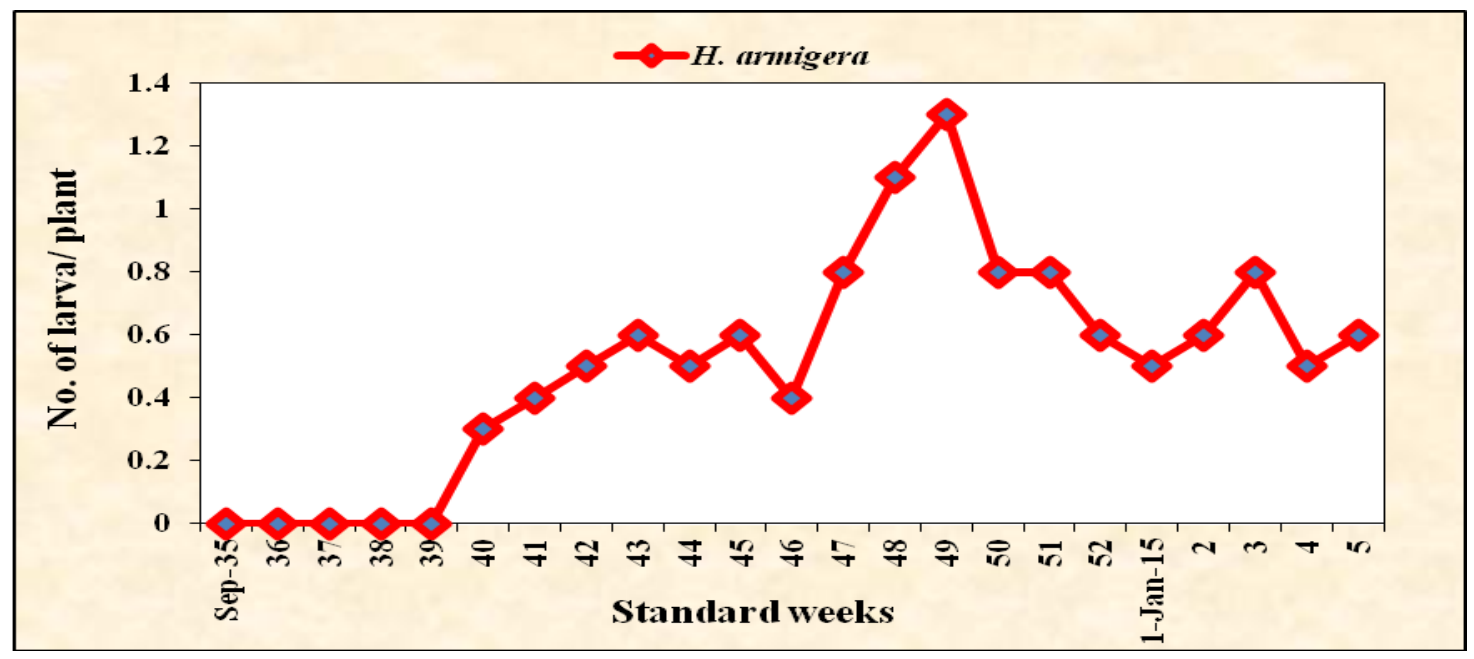


Fig.2 Incidence of per cent fruit borer damage on ashwagandha during 2014-15

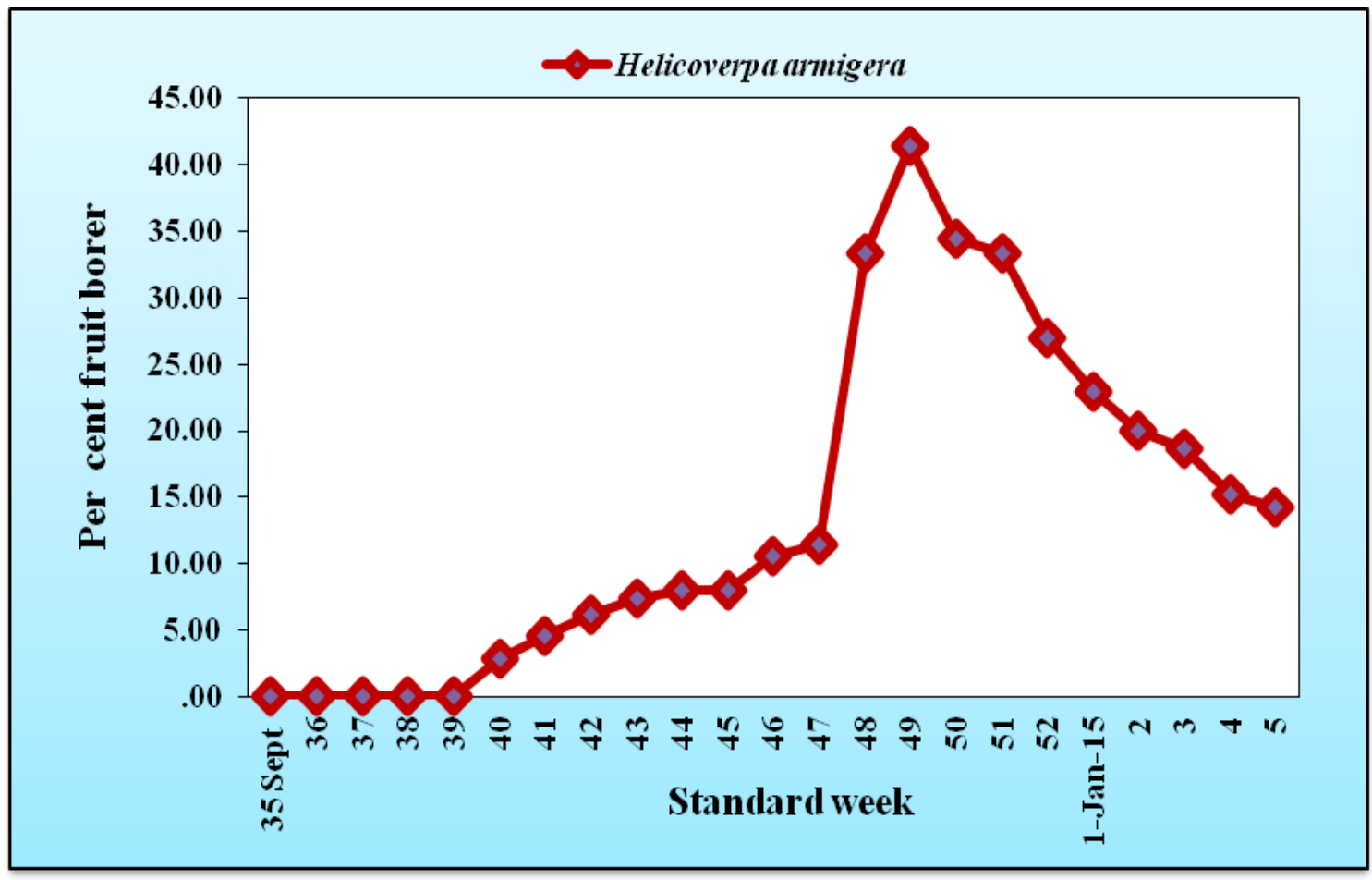

Fig.3 Relationship between maximum temperature $\left({ }^{0} \mathrm{C}\right)$ and minimum temperature $\left({ }^{0} \mathrm{C}\right)$ with incidence of $H$. armigera on ashwagandha

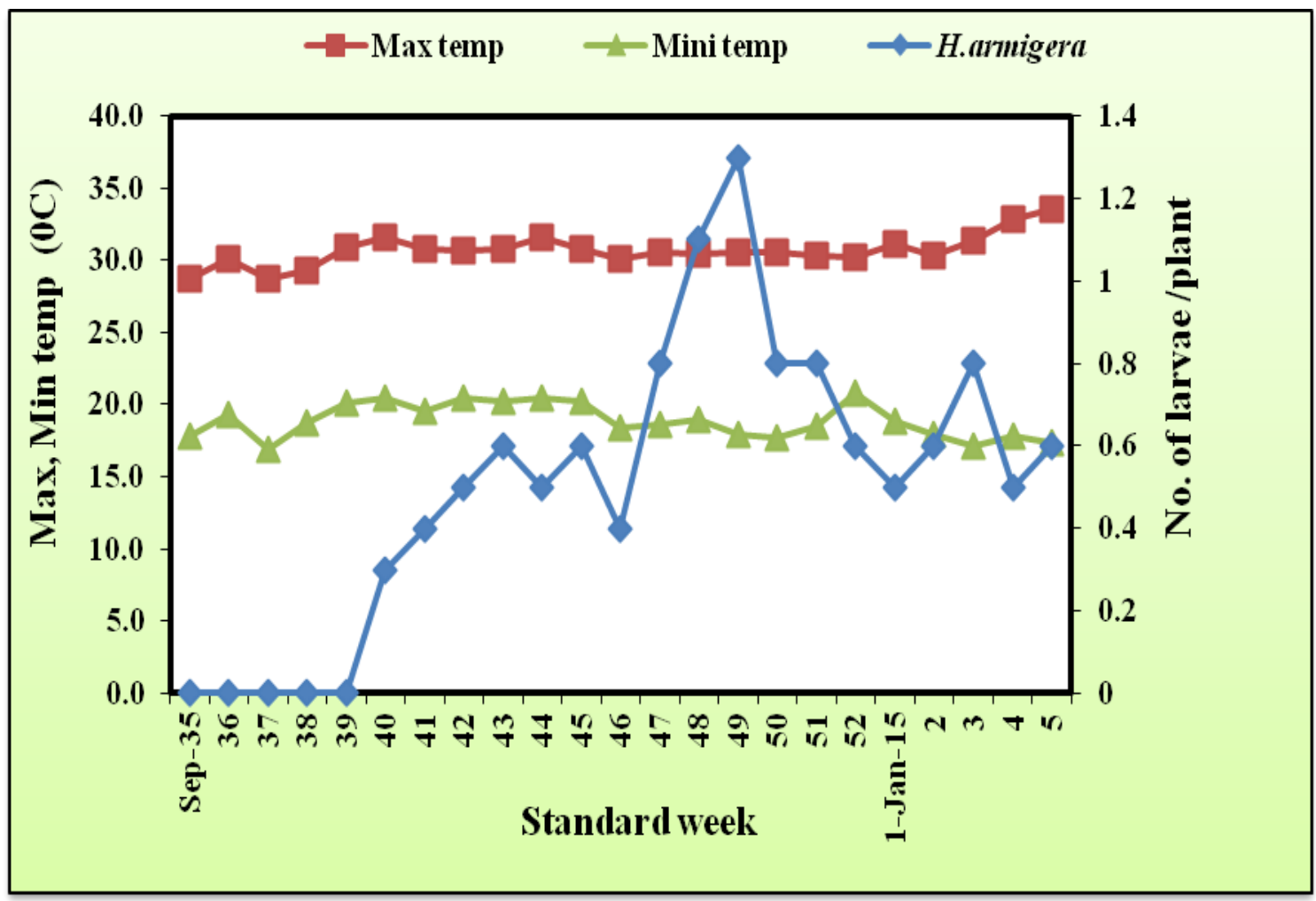


Fig.4 Relationship between morning (Rh1) and evening (Rh2) relative humidity (\%) with incidence of $H$. armigera on ashwagandha

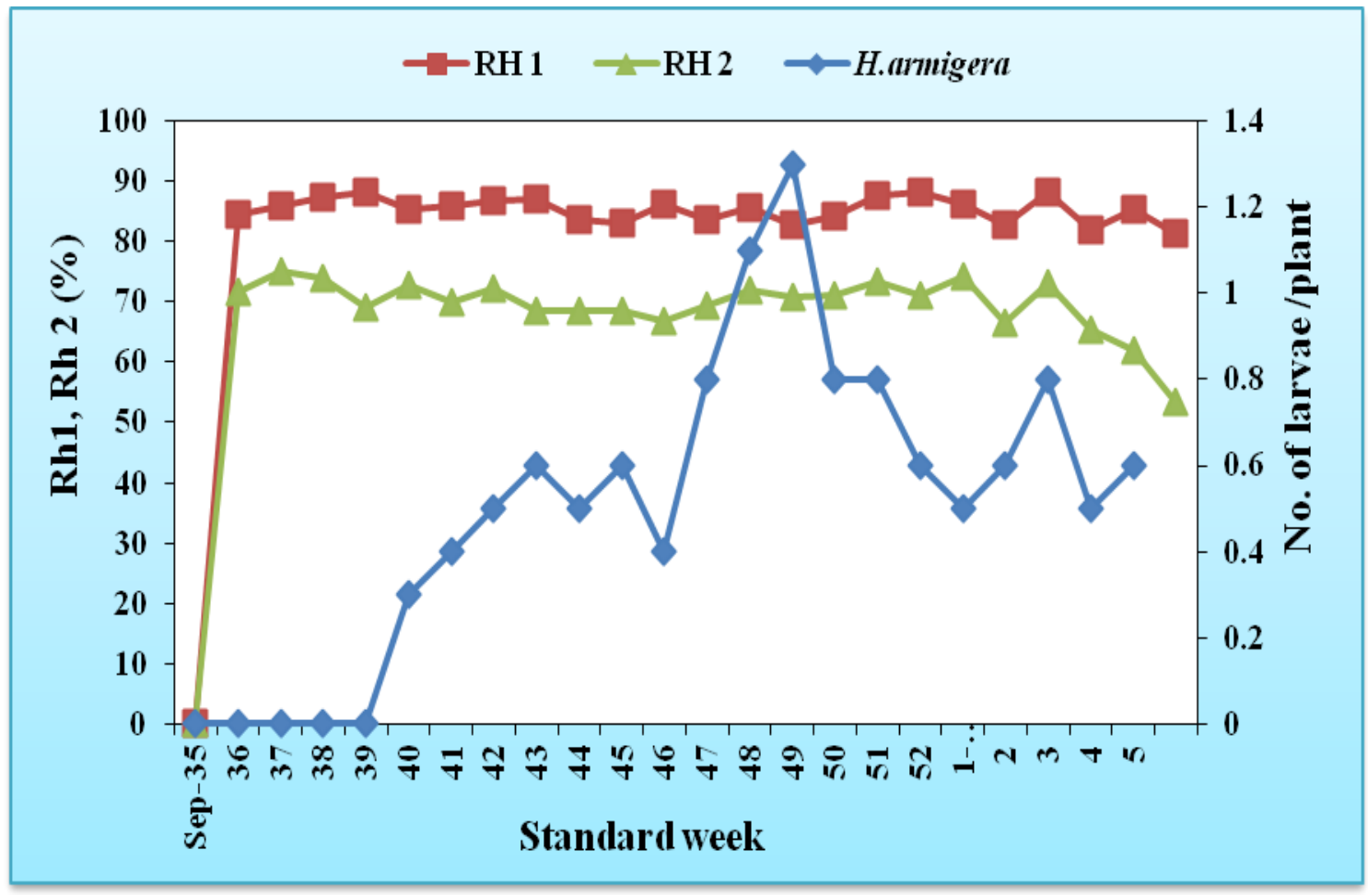

Fig.5 Relationship between rainfall (mm) with incidence of $H$. armigera on ashwagandha

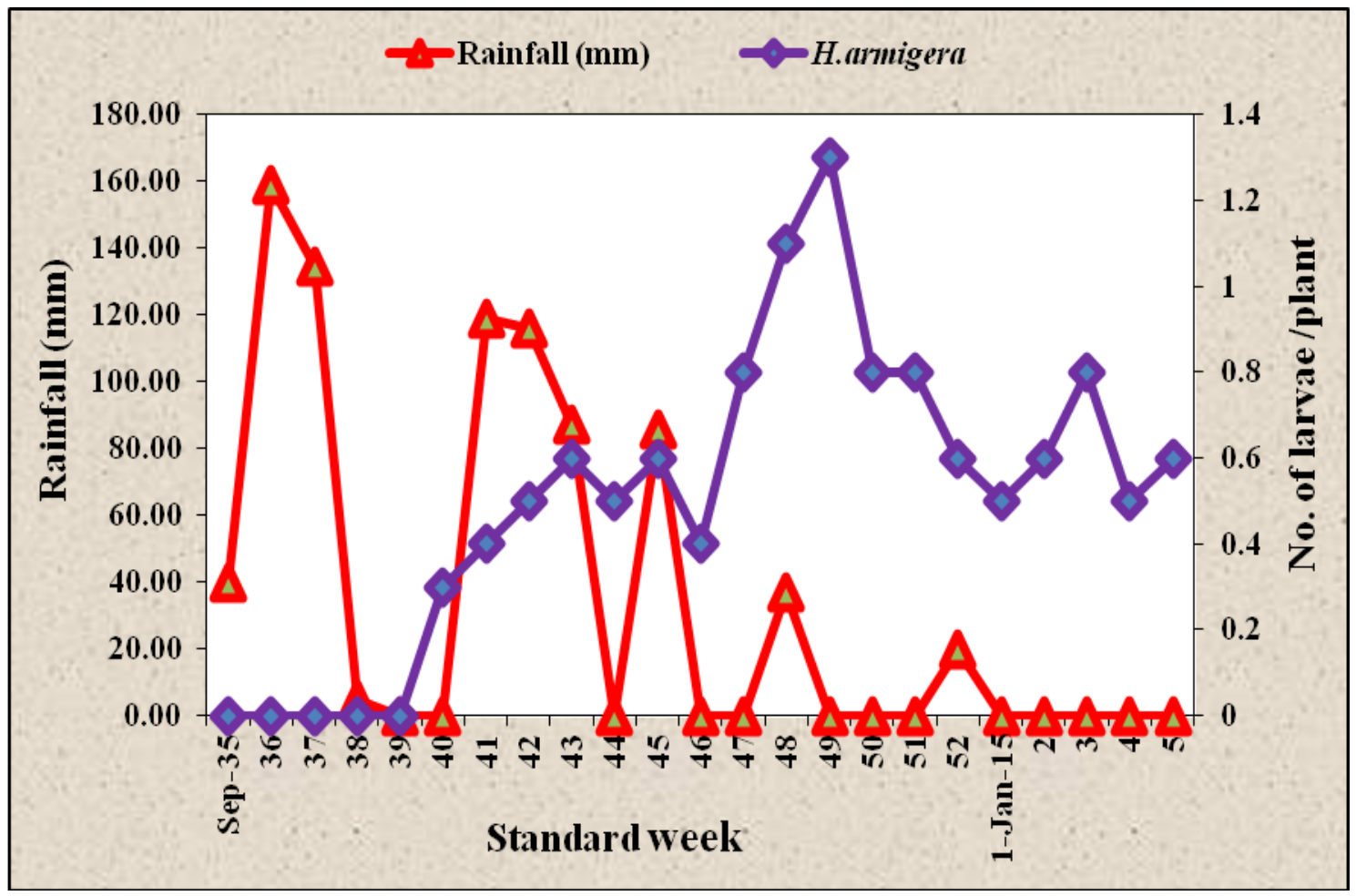


Plate.1 Incidence of Helicoverpa armigera on Ashwagandha at OFRC, Shivamogga
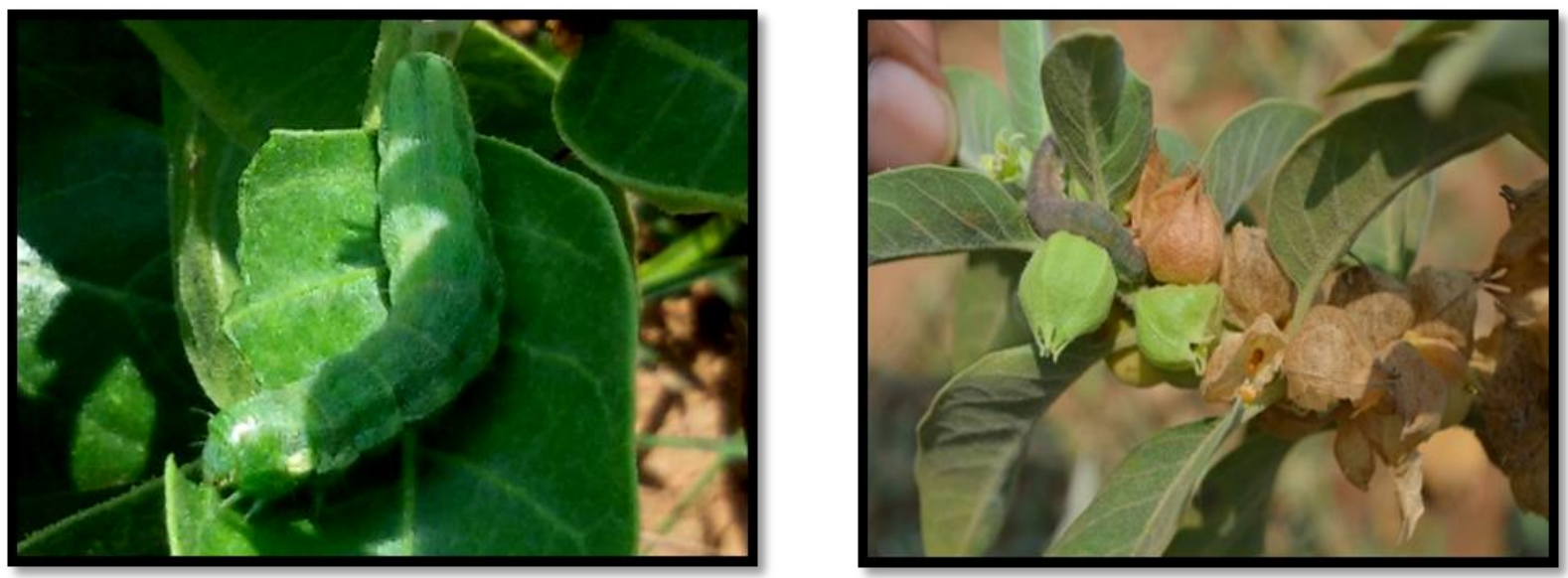

Larvae of $H$. armigera

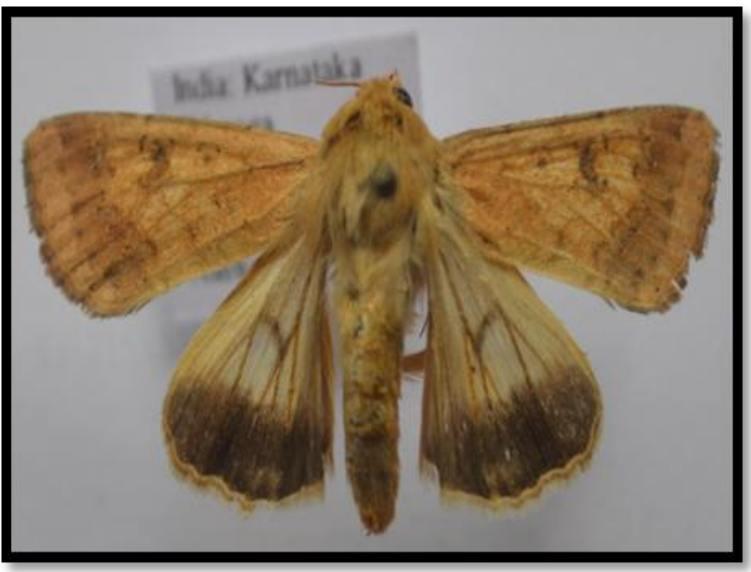

Adult of H.armigera
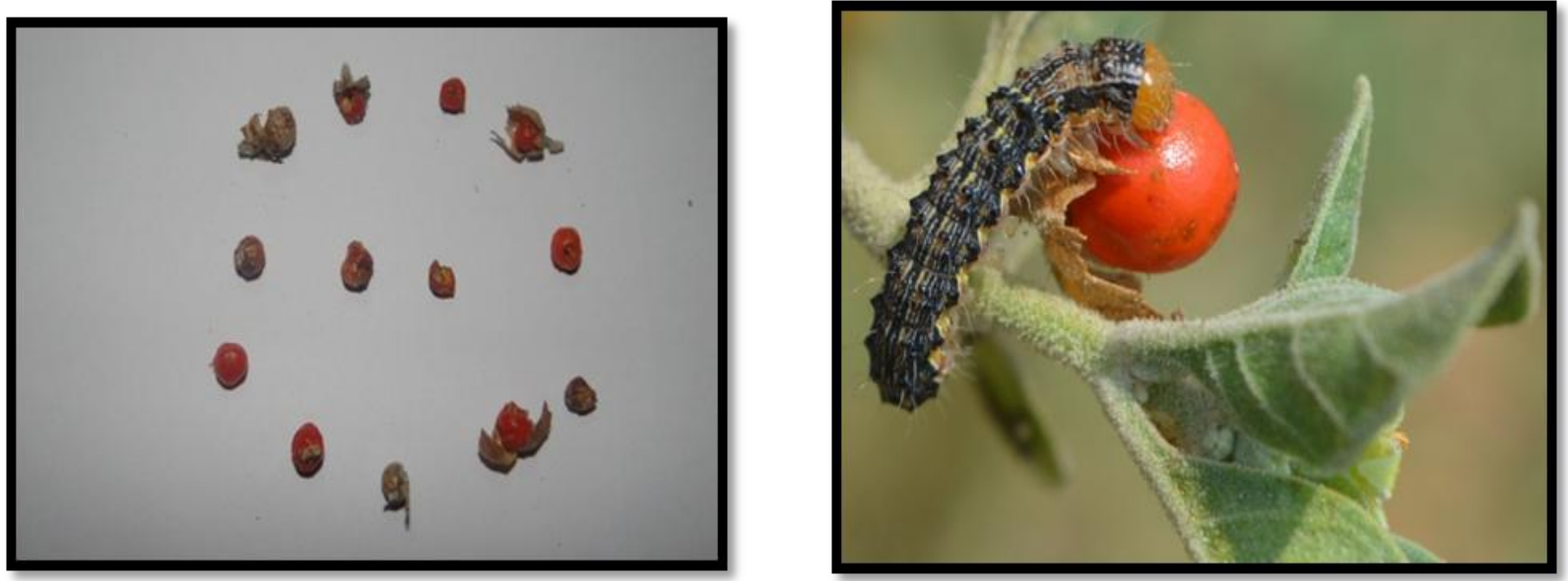

Fruit damaged by $H$. armigera 
The correlation studies made between incidence of per cent fruit borer damage and weather parameters revealed that, evening relative humidity $(r=-0.004)$ showed negative and nonsignificant relationship, whereas rainfall $(\mathrm{r}=$ $\left..456^{*}\right)$ showed negative and significant relationship with percentage of fruit borer damage. Maximum temperature $(r=0.168)$ had positive and showed non-significant relationship whereas minimum temperature $(r=-0.242)$ and morning relative humidity $(\mathrm{r}=-0.114)$ had negative correlation and showed non-significant relationship with percentage of fruit borer damage. The results obtained are in confirmation with findings of Sivaprakasam (1996) on tomato fruit borer. Similarly, Raodeo et al., (1983) who reported that the population of Helicoverpa armigera on Cotton was reported to be negatively correlated with rainfall (Figure 3, 4 and 5).

The multiple linear regression equation was fitted to the data and equation found was. (Table 3 )

$\mathrm{Y}=-146.36-0.371 \mathrm{X}_{1}+0.456 \mathrm{X}_{2}-0.32 \mathrm{X}_{3}-$ $0.09 \mathrm{X}_{4}+0.331 \mathrm{X}_{5}$

Where, $\quad \mathrm{X}_{1}=$ Rainfall $\quad(\mathrm{mm}) ; \quad \mathrm{X}_{2}=$ Maximum temperature $\left({ }^{0} \mathrm{C}\right) ; \mathrm{X}_{3}=$ Minimum temperature $\left({ }^{0} \mathrm{C}\right)$; $\mathrm{X}_{4}=$ Morning Relative humidity $1(\%) ; \mathrm{X}_{5}=$ Evening Relative humidity 2(\%).

This explains that every increase in one unit of rainfall, minimum temperature, morning relative humidity will decrease per cent fruit borer damage by $-0.371,-0.32$, and -0.09 units, respectively. Whereas every increase in one unit of maximum temperature and evening relative humidity will increase the percent fruit borer damage by 0.0456 and 0.331 units, respectively. The weather factors influenced per cent fruit borer damage to the extent of 33 per cent. The maximum population of larval incidence and per cent fruit borer damage on Ashwagandha was peak during third week of
December i.e., 1.3 larvae per plant and 41.40 per cent respectively. A non-significant correlation was observed between the larval population of $H$. armigera and weather factors. The correlation between fruit damage and weather factor was found negatively significant to rainfall and nonsignificant to temperature and relative humidity.

\section{References}

Chandranath, H. T. and Katti, P. 2010. Management of Epilachna beetle on ashwagandha. Karnataka Journal of Agricultural Sciences, 23(1): 171.

Ramanna, D., Kumar, P. and Basavana Goud, K. 2010. Pest complex of medicinal plants. Karnataka Journal of Agricultural Sciences, 23(1):197-199.

Rammana, D., 2009. Investigations on pest complex of medicinal plants and their management with special reference to Ashwagandha (Withania somnifera Linn.), M. Sc. (Agri.) Thesis, University of Agricultural Sciences., Dharwad.

Raodeo, S., Jagtap, C. R., Shetgar, S. S. and Nalwandikar, 1983. Population dynamics of Lepidopterous pests of okra in relation to weather factors during summer. Journal of Maharashtra Agricultural University, 33 (2): 201-203.

Sangwan, R. S., Chaurasiya, N. D.,Misra, L. N., Lal, P., Uniyal, G. C., Sharma, R., Sangwan, N. S., Suri, K.A., Qazi, G. N. and Tuli, R. 2004. Phytochemical variability in commercial products and preparations of Withania somnifera (Ashwagandha). Current Science, 86: 461-465.

Sivaprakasam, N., 1996. Influence of weather factors on the attraction of Helicoverpa armigera (Hubner) on tomato. Pest management in Horticultural Ecosystem, 2 (2): 87-88.

\section{How to cite this article:}

Syed Khadeeru Rehaman, S. Pradeep and Dhanapal, R. 2018. Incidence of Fruit Borer Helicoverpa armigera (Hubner) on Ashwagandha in Shivamogga. Int.J.Curr.Microbiol.App.Sci. 7(03): 1060-1066. doi: https://doi.org/10.20546/ijcmas.2018.703.126 